\author{
П.П. Бражников
}

\title{
ВЗАИМОДЕЙСТВИЕ СИСТЕМЫ СО СРЕДОЙ НА ПРИМЕРЕ ФОРМИРОВАНИЯ ПСИХИКИ ЧЕЛОВЕКА
}

\begin{abstract}
Аннотация. Цель данной статьи расширить применение теории систем в области психологии человека. Приводятся некоторые положения из теории систем, представлена общая модель взаимодействия систем и окружающей среды. В модели утверждается, что деятельность систем зависит от характеристик окружающей среды. На основе предложенной системной модели рассматривается процесс развития и формирования психики человека. Человек рассматривается как система, адаптирующаяся в незнакомой среде. Показано, как окружающая среда влияет на метод мышления человека и анализ им внешней информации. Большое внимание также уделяется специфике работы разных полушарий мозга. Статья состоит из двух частей. В первой части статьи выделены четыре основных типа взаимодействия системы и среды, которые зависят от характеристик среды относительно параметров системы. Таких характеристик две: во-первых, количество ресурсов, во-вторых, предсказуемость его изменения. Для каждого набора характеристик среды взаимодействие системы с ней будет различным. В тоже время важно, источники каких сигналов преобладают в среде, полезных или разрушающих, от этого будет зависеть направленность системы к источникам или от них. Однако окружающая среда редко бывает однородна для системы, в ней возможны источники сигналов различной морфологии. В таком случае каждый вид сигналов формирует составляющую среды с независимыми характеристиками. Соответственно и взаимодействие системы $c$ каждым видом сигналов будет различным.
\end{abstract}

Во второй части статьи на основе данной модели рассматривается процесс развития психики человека. Утверждается, что в процессе развития человек сталкивается с двумя видами внешних источников сигналов: физические объекты и социальные субъекты. Соответственно, с каждым из них возможны четыре типа взаимодействия и два типа направленности относительно источников. При этом важно распределение работы по взаимодействию с этими видами ресурсов между полушариями мозга. Эти факторы влияют на итоговый способ мышления человека и его анализ внешней информации.

Ключевые слова: теория систем, психология развития, взаимодействие со средой, темперамент, типология Юнга, работа полушарий мозга, аутизм, шизофрения, формирование психики, стадии развития.

Abstract. The purpose of this article is to expand the application of the systems theory to the human psychology sphere. Some of the theses of the systems theory and the general model of the interaction of systems and environment are shown. The model states that the activities of systems depend on characteristics of their environment. The process of development and formation of the human psyche is explored on the basis of the proposed system model. An individual is explored as a system adapting to an unfamiliar environment. The author shows how the environment affects a human method of thought and analysis of external information. Much attention is also paid to the specifics of the different hemispheres of the brain. The article consists of two parts. In the first part four major types of system interaction and the environment are shown. Those depend on characteristics of the environment with reference to system parameters. There are two kinds of system parameters: firstly, the quantity of resourses, and secondly, predictability of changes. For each set of environment characteristics, the environment interaction with the system will be different. At the same time it is important which signal sources are prevalent in the environment, beneficial or destructive, because an orientation of a system towards the sources or from them will depend on this. However, the environment is rarely homogeneous for the system as there may be sources of signals of various morphology. In such case, each type of signals forms a constituent of an environment with independent characteristics. Therefore, the interaction of the system with each type of signals will be different. In the second part of the article the process of the human mind development is investigated on the basis of aforesaid model. It is asserted that during his or her development a person is faced with two types of external signal sources: physical objects and social subjects. Consequently, with respect to each of these four types of interaction and two types of 
orientation relatively of sources may take place. Simultaneously, the allocation of actions for interaction with these kinds of resources between the brain hemispheres is important. These factors influence on an established personal method of thought and analysis of external information.

Key words: autism, schizophrenia, cerebral hemisphere's operation, Jung typology, temperament, interaction with the environment, developmental psychology, systems theory, organization of mind, developmental stages

\section{Введение}

Человек является, как и любой организм или организация, системой, взаимодействующей с окружающим миром. Изучение человека с данной позиции позволяет применять положения теории систем. Именно с рассмотрения некоторых общих для всех систем закономерностей и начинается данная статья.

Системы состоят из элементов, взаимодействующих для достижения общей цели [1]. Структура системы, её элементы и связи между ними, характеризуют наличие некоторой информации, содержащейся в её объёме. Если рассматриваемые объекты не связаны, то и какая-либо информация в их множестве отсутствует. Чем больше группа связанных объектов, чем массивнее состоящий из них предмет, тем больше в нем информации. Также, количество информации тем больше, чем сложнее связи между элементами системы. Можно упрощённо сказать, что чем сложнее описать расположение объектов и свойства этих объектов, тем больше в их множестве содержится информации. Если множество одинаковых объектов неподвижно, информации минимум. Если они движутся, но строго по прямой, информации больше. Ещё её больше - если объекты движутся прямолинейно, но могут изменять траекторию вследствие столкновений. Если объекты не равны, а, скажем, имеют различные размеры - то информация также увеличивается. Если расположение объектов более сложным образом зависит от других компонентов множества, или если они не однородны, то описание такой системы значительно усложняется - увеличивается информация, содержащаяся в ней.

Одновременно с ростом количества информации в системе увеличивается энергия, содержащаяся в ней. Это связано с тем, что энергия требуется для построения сложных взаимодействий. Можно провести аналогию между объёмом информации и понятием энтальпии, которая также связана с содержанием энергии.

Единственная функция любой системы - адаптация к внешним условиям с целью максимального сохранения своей структуры [2]. Первичная характеристика системы всегда строится исходя из её свойств - внешних проявлений. Только после этого можно сделать предположения о её струк- туре. Внешние свойства систем проявляются во взаимодействии с внешними системами. Такая коммуникация происходит либо напрямую, либо опосредованно через другие системы. В любом случае происходит обмен информацией, под которым подразумевается изменение физической структуры одной или нескольких систем. Если обмен информацией устойчив - создаётся общая для данных систем надсистема.

Каждой системе, для сохранения её структуры и свойств, требуются внешние ресурсы, внешняя информация [3]. Ресурсы, требующиеся для поддержания системы, должны иметь структуру, легко преобразуемую в структуру системы, близкую к ней. Отсюда, для более сложных систем, требуются ресурсы с большим содержанием информации [4]. Такие ресурсы являются, по сути, также системами. Получая из внешней среды ресурсы, система перенаправляет их энергию, содержавшуюся в информации, на другие взаимодействия с внешней средой. Эти взаимодействия могут быть либо дезорганизующие, либо более организующие для внешних систем [5]. Сама система при взаимодействии может также изменяться, адаптируясь к среде.

Внешние условия, а именно характеристики ресурсной базы, существенно влияют на деятельность систем [6]. В первую очередь, важна предсказуемость источников ресурсов [7; 8]. Второй основополагающий критерий - количество ресурсов. Этих критериев достаточно для оценки ресурсной базы. Все остальные критерии сводимы к этим двум. Например, качество ресурсов, лишь уменьшает их эффективное, доступное системе, количество в объёме. Другой пример - равномерность порций, которая, при одинаковом среднем, будет влиять на предсказуемость. Важно также не путать вероятность получения ресурсов и предсказуемость. При любых значениях вероятности, выживать будут системы, которым больше повезёт. Вероятность может не зависеть от поведения и характеристик систем. В такой ситуации, общих черт, характерных для систем при определённой ресурсной базе, выделить не будет возможности. Напротив, предсказуемость ресурсов будет напрямую влиять на адаптацию систем к условиям, дающим большую вероятностью выигрыша.

И количество, и предсказуемость ресурсов не могут быть абсолютными величинами. Их необ- 


\section{Психология и психотехника 8(95) • 2016}

ходимо оценивать относительно характеристик системы. Количество оценивается относительно её потребностей, а предсказуемость - относительно степени зависимости от текущей деятельности системы. Указанные критерии дают четыре принципиально различных типа ресурсной базы по отношению к конкретной системе. Первый - непредсказуемая и скудная, без возможности накапливать ресурсы и не зависящая от интенсивности свойственных системе действий. Второй тип ресурсной базы - скудная, но предсказуемая, увеличивающаяся при усилении некоторых активностей системы. Третья - непредсказуемая, но обильная, позволяющая накапливать излишнюю энергию. И последний, четвёртый тип - предсказуемая и обильная. Конечно, данные характеристики могут быть не постоянны и изменяться, но при достаточной длительности они вынуждают адаптироваться к ним [9].

Непредсказуемая и скудная окружающая среда сделает наиболее выгодной стратегией выжидание в состоянии наименьших затрат энергии. Также, при появлении ресурсов в такой среде требуется быстрая реакция, чтобы их не упустить. У такой стратегии могут быть различные частные проявления при неопределённости ресурсов либо во времени, либо в пространстве, либо при обеих неопределённостях. Хорошо подходят для иллюстрации такой стратегии кактусовые растения или пауки. Если говорить о людях, как о системах, то можно провести аналогию с сангвиническим темпераментом [10].

Другой случай, когда среда скудна, но предсказуема, что означает некоторую зависимость от каких-либо проявлений системы. Данная зависимость от действий может быть косвенной и незначительной. В случае предсказуемости среды для выживания системе потребуется увеличить эффективность своих действий, сосредоточившись на наиболее влияющих на результат. А также адаптируя эти действия. Последнее производится небольшими и редкими отклонениями от известных алгоритмов, для исследования возможного увеличения эффективности. Если отклонение от алгоритма не даёт выигрыша в получении ресурсов, изменения не закрепляются, и наоборот. Таким образом система приспосабливается, достигая возможного максимума эффективности. По его достижении, установившийся алгоритм действий непрерывно и строго выполняется, лишь с редкими краткими отклонениями. Установившийся алгоритм может не быть самым эффективным из возможных, однако он будет самым эффективным из доступных при данной отправной точке. Описанную страте- гию медленной адаптации хорошо демонстрирует большинство растений, а также колонии общественных насекомых. Среди темпераментов людей можно провести аналогию с флегматиками.

Если среда может обеспечить непредсказуемые, но избыточные для текущих потребностей системы ресурсы, то появляется возможность накопления. Тогда адаптируясь, системы будут увеличивать эффективность сохранения избыточной энергии. При значительных запасах, они смогут тратиться на периодический активный поиск и захват новых источников ресурсов. Такая стратегия в существенной степени свойственна многим крупным хищникам. Также ей хорошо соответствуют люди с холерическим темпераментом. С другой стороны, при большем влиянии временной неопределённости, нежели пространственной, системы повысив эффективность хранения и расходования энергии, просто увеличат возможный период пассивного ожидания. Наглядными примерами являются многие змеи и крокодилы, обитающие в местах водопоя. Обе стратегии используют направление избытка ресурсов на снижение эффекта непредсказуемости либо в пространстве, либо во времени. Часто встречаются смешанные стратегии. При данной стратегии также, как и первой, требуется быстрая реакция.

Последний тип ресурсной базы по отношению к конкретной системе - предсказуемая и обильная. В данном случае системе не требуются увеличивать эффективность ни накопления, ни деятельности по достижению ресурсов. Более того, появляется возможность избавиться от излишних имеющихся алгоритмов повышения эффективности. Происходит некоторое упрощение или дезорганизация систем. В случае истощения имеющегося источника, практически все оставшиеся запасы будут потрачены на активный поиск нового источника. Примерами систем, существующих в подобных средах, могут служить большая часть бактерий и настоящих мух. Люди, чья среда позволяет следовать данной стратегии, имеют холерический темперамент.

Только что мы рассмотрели классификацию источников ресурсов относительно характеристик систем. Для классификации мы использовали только два основных параметра. Тогда системы, взаимодействующие с данными источниками ресурсов, также можно классифицировать по двум параметрам. Так как среда в большей степени влияет на субъекты в ней, по сравнению с влиянием последних на среду, то классификация систем должна быть по их реакциям [11]. Базовыми параметрами реакции являются чувствительности по длитель- 


\section{Психология развития}

ности и по величине внешнего сигнала. Длительность и величина сигнала, также как и параметры среды, относительны по сравнению с характеристиками системы. Длительность внешнего сигнала важна по сравнению со скоростью метаболизма системы, а величина сигнала с общим объёмом анализируемой системой информации. Диапазон чувствительности систем не может быть широким, поэтому при изменении среды диапазон чувствительности смещается [12]. Например, если система реагирует на короткий сигнал, то при длительном сигнале реакции уже не будет. В противном случае система растратила бы всю энергию на ответные действия. Тоже и с силой внешнего сигнала. Поэтому никакая система на может быть классифицирована более чем одним типом реакции для каждого отдельного типа сигналов или ресурсов.

При скудной и непредсказуемой среде требуется реагировать даже на короткие и слабые внешние сигналы, связанные с ресурсами, доступными системе для переработки. Другими словами нижний порог чувствительности системы будет низким как по длительности, так и по величине. Когда среда скудна, но предсказуема, реакция, т.е. смена алгоритма действий, произойдёт лишь при длительном падении эффективности. Нижний порог чувствительности будет при слабом, но долгом внешнем сигнале. Системы, адаптированные к крупным источникам ресурсов, будут иметь высокие пороги чувствительности по величине входного сигнала. Но при непредсказуемых ресурсах требуется быстрая реакция на короткие сигналы, а в противоположном случае - лишь реакция на длительное ослабевание внешних источников. Таким образом получается четыре основных типа поведения систем [13].

Описанные выше четыре типа взаимодействия системы с внешней к ней средой не являются характеристикой целой системы. Ни один из них не может соответствовать целиком всем сферам её активности. Большинство известных систем потребляет несколько различных типов ресурсов, т.е. различную информацию на различных носителях информации, внешних системах. Для каждого типа внешних ресурсов будет свой тип взаимодействия со средой, как и носитель, редко зависящий от других. Например, кислород практически все сухопутные животные получают одинаково - непрерывно малыми порциями. В тоже время, например еда, как ресурс, имеет самую разную доступность. Различные типы носителей информации, внешних систем, можно назвать каналами обмена информацией. Выше упоминались темпераменты людей для иллюстрации различных типов взаимодействия.
Подразумевалось прямое взаимодействие человека с окружающими людьми, именно этот канал коммуникации характеризует темперамент. Отношения человека, для примера, к пище или работе могут характеризоваться иным типом.

Помимо получения ресурсов, система, адаптируясь, должна развивать способы противодействия внешним дезорганизующим воздействиям. Таким воздействием является внесение в систему информации, создающей помехи для внутренних сигналов между подсистемами. Адаптируясь к окружающей среде, т.е. изменяя своё строение и свойства, система может включать в свой состав внешние структуры, образуя с ними большую устойчивую организацию. Для устойчивости новой конструкции требуется постоянный обмен информацией, т.е. изменение строения некоторых элементов будущей надсистемы. Если во время взаимодействия двух систем появится третий источник информации в том же канале, с тем же носителем, то он будет вносить шумы в коммуникацию первых двух систем. Чем интенсивнее шум, тем слабее будет связь через данный канал, а значит, тем неустойчивей будет общая надсистема, взаимодействующая через носители информации этого типа.

Внешние угрозы целостности системы, источники дезорганизующей информации, также можно поделить на типы, по базовым критериям. Эти критерии будут схожи с критериями источников ресурсов: предсказуемость и интенсивность. Соответственно зависимость свойств систем от различных типов опасностей будет схожа с зависимостью от типа ресурсной базы. Основное отличие будет в том, что движение теперь будет в сторону, противоположную источнику внешнего сигнала.

В непредсказуемой и слабо опасной среде, с низкоинтенсивными источниками шумов, потребуется быстрая реакция на угрозы. Однако реакция может быть достаточно экономичная, так как источник дезорганизующего воздействия в большинстве случаев ограничен либо пространственно, либо во времени. Экономичной реакцией может быть либо небольшое изменение положения, либо изменение состояния, не требующее значительных затрат. Последнее возможно когда безопасное состояние заранее подготовлено, как, например, у ежей, улиток и осьминогов, способных выпускать маскирующие чернила.

В слабо опасной и предсказуемой среде ведущей стратегией будет постоянное выполнение действий, снижающих угрозу. Примерами могут служить животные, маскирующиеся под иные объекты, меняющие окраску, строящие искусственные убежища или вырабатывающие яд на своей поверхности. 


\section{Психология и психотехника 8(95) • 2016}

Если среда мало предсказуема и содержит источники с сильно разрушающим воздействием, то помимо быстроты реакции становится критична и её интенсивность. В такой среде системы могут также действовать различными методами. Возможно, для примера, существенно изменить своё положение или его предсказуемость. Или же проявить опасные для источника угрозы свойства. В животном мире используется увеличение в размерах, выстрел ядом, нападение заострёнными выростами и т.д. Такая активность требует немалых затрат энергии и длительности для большей гарантии результата.

Последний из основных типов среды характеризуется высоким уровнем опасности, но её источники хорошо предсказуемы. В такой среде достаточно избегать действий, могущих повысить внешнюю угрозу. Какие-либо дополнительные действия в большинстве случаев не требуются. Такая стратегия хорошо иллюстрируется отношением животных к ядовитым объектам.

Описанные выше типы реакции на опасность, повторяют четыре типа взаимодействия системы со средой для получения ресурсов, но имеют другое направление движения. К получившимся четырём типам реакции на внешнюю угрозу можно также свести, например, типы психологической защиты человека [14]. Характеристики внешних угроз могут не совпадать с характеристиками внешних ресурсов. В качестве примера допустимо привести крупных травоядных животных в тёплых регионах. Доступные им пищевые ресурсы предсказуемы, но в малых порциях. В тоже время, нападения хищников носят неожиданный и часто смертельный характер. Соответственно, взаимодействия с ресурсами и с хищниками происходят по различным стратегиям.

Любое взаимодействие системы с внешними структурами приводит либо к противоречию и дезорганизации, либо к соответствию во взаимовыгодных процессах и развитию. Поэтому указанные четыре типа реакций и два типа их направленности упрощённо описывают все множество активностей системы. Конкретный тип коммуникации и её направленность по каждому каналу, через различные носители, зависит от конкретных характеристик внешних сигналов в данном канале.

Велика вероятность случаев, когда в одном канале коммуникации внешняя среда содержит и ресурсы и угрозы. В тоже время невозможно одновременно и генерировать сигналы и блокировать их. По этой причине активная система может иметь лишь одно приоритетное направление по каждому каналу, зависящее от предыдущего опыта.

\section{Развитие человека}

Как было сказано в начале, мы будем рассматривать человека как систему [15]. Большинство биологических систем, животных, основную адаптацию к устойчивым факторам среды осуществляет через эволюцию [16], в том числе через механизм инстинктов. Человека же мы будем рассматривать как систему с гораздо более совершенными и быстрыми механизмами адаптации через индивидуальный опыт. В таком случае придётся отказаться от предположения, что человек обладает какимилибо инстинктами. Последнее утверждение достаточно обосновано, так как у человека отсутствуют заложенные с рождения алгоритмы действий, одинаково проявляющиеся у всех представителей вида. Единственное проявление человека, которое может соответствовать определению инстинкта копирование мимики взрослых младенцев. Однако накопилось достаточно исследований опровергающих инстинктивную природу такого поведения $[17 ; 18 ; 19]$. Инстинктивная природа прочих паттернов поведения, включая такие «инстинкты» как «инстинкты» самосохранения и размножения, также давно ставится под сомнение [20; 21]. Отсутствие инстинктов, конечно, не опровергает наличие простейших рефлексов. Последние являются реакцией, проходящей часто даже без участия головного мозга [22].

Другое важное свойство человека, как и многих других биологических систем - наличие двух достаточно независимых устройств обработки информации, полушарий головного мозга. Информация соответствует энергии, содержащейся в структурах. Следовательно, обработка информации необходима для приёма и передачи энергии. Усложнение системы обработки информации делением на два потока позволяет с большей эффективностью взаимодействовать через два крупных канала коммуникации со средой. Такая структура является следствием необходимого повышения сложности при росте количества учитываемых факторов [23]

При взаимодействии со средой системы стремятся изменить либо себя, если среда предсказуема, либо окружающие структуры, если среда непредсказуема. Эти два способа адаптации аналогичны, соответственно, приоритету восприятия информации и приоритету её трансляции. Наличие двух полушарий мозга позволяет разделить обработку принимаемой и транслируемой информации между ними, для ускорения процессов адаптации, как самой системы, так и её среды [24; 25]. К тому же два полушария позволяют 
разделить тактическую и стратегическую работу. Что важно, поскольку фокусы внимания тактики и стратегии значительно различаются: текущие явления и долгосрочные тенденции, соответственно. Также мы предполагаем возможным разделение между полушариями мозга активностей по достижению ресурсов и по устранению угроз. Разделение каналов обработки информации между полушариями имеет место и в некоторые других областях.

Только одна специфика полушарий имеется с рождения: правому полушарию характерно образное восприятие текущего состояния самого человека и внешней среды, левому свойственны анализ и поиск закономерностей [26]. Данное различие приводит к тому, что правое полушарие больше влияет на непосредственные проявления человека в текущих ситуациях, аналогично тактике. Ocoбенность работы левого полушария имеет первым следствием то, что оно в большей степени влияет на долгосрочные особенности деятельности человека, фактически, его стратегию. Также можно охарактеризовать это разделение правого и левого полушария как новизна и рутина, соответственно [27]. Можно также провести аналогию с двумя накладывающимися частотами модуляции внешних структур, быструю и более медленную, огибающую. Более подробно о специфике полушарий мозга будет рассказано далее.

Если у человека отсутствуют инстинкты, то процесс адаптации должен начинаться с появлением восприятия, которое возникает ещё до рождения [28]. Перед тем, как начать вырабатывать какой-либо из типов взаимодействия с окружающим миром, человеку как системе придётся определить направление своей активности: положительное, к ресурсам, или отрицательное, от угроз [29]. После выбора направления непосредственной, тактической, деятельности связанной с правым полушарием, левое полушарие по остаточному принципу начнёт обработку противоположно направленной информации. Если по какой-либо причине оба полушария приобретут равные свойства по отношению к окружающей среде, система не сможет либо эффективно избегать угроз, либо получать ресурсы. Данное разделение полушарий по свойствам происходит либо до рождения, либо в процессе него [30].

Независимо от направленности полушарий, дальнейшие события будут абсолютно непредсказуемы для ребёнка. Величина же внешних сигналов будет низкой, неудобства относительно не разрушительны, а поступающих ресурсов хватает ненадолго. Получается, что и свойства системы в подобной среде должны быть соответствующими: экономичное ожидание, сменяющееся быстрой, но относительно не затратной реакцией. Единственные доступные системе ресурсные или безопасные состояния будут связаны с внешней обстановкой и с привычными взрослыми. Опасные же состояния будут связаны либо с физическим дискомфортом, либо с незнакомыми объектами. Именно изменение этих факторов и будут вызывать самые сильные эмоции, в зависимости от направленности правого полушария. В этот период арсенал действий человека не велик.

Со временем у ребёнка появляются возможности физического воздействия на окружающие предметы. Тогда возможности адаптации существенно возрастают. У ребёнка мало возможностей адаптации изменением себя, но он может создать более крупную надсистему, включающую его самого и некоторые внешние объекты. В этом случае появится возможность адаптироваться изменением такой надсистемы [31]. Например, создав некоторое безопасное личное пространство с известными объектами, расположенными в известном порядке, в котором с большой вероятностью отсутствуют источники опасности [32]. Либо накапливая предметы, связанные с положительными эмоциями. Эта деятельность будет большей частью связана с правым полушарием. Левое к этому моменту, возможно, сможет систематизировать зависимость поведения взрослых от действий ребёнка, на основе опыта, полученного до физической манипуляции с объектами.

Все действия по манипуляции внешними объектами, для создания надсистемы, будут соответствовать внесению во внешнюю среду новой информации. Носителями информации будут сами объекты. Для итоговой надсистемы разрушающим внешним воздействием будет перемещение объектов, входящих в неё. Если извне перемещаются объекты, собранные ребёнком и связанные с положительными эмоциями, то внешнее вмешательство будет аналогично уменьшению количества полученного ресурса и его предсказуемости. Если окружающая человека среда устойчиво проявляет себя как непредсказуемая, то человек вынужден сосредоточиться на соответствующем типе взаимодействия с нею [33]. Так как речь идёт о правом полушарии, то такие приобретённые человеком свойства будут проявляться в общении и в непосредственной деятельности. К. Юнг назвал подобное отношение к объектам «экстравертный ощущающий тип» [34].

Если же создание надсистемы, включающей внешние объекты, будет успешным, то внешняя 


\section{Психология и психотехника 8(95) • 2016}

среда станет предсказуемой. В этом случае правое полушарие вынуждено будет изменить способ взаимодействия с нею. Деятельность систем в такой среде направлена на увеличение своей эффективности через поиск оптимальных алгоритмов действий. Ребёнок начинает изучать способы действий с предметами [35; 36; 37]. Таким образом надсистема из человека и объектов в его личном пространстве дополняется дополнительными знаниями человека об использовании данных объектов [38]. Происходит изменение самого человека как системы, его восприятие информации. Этот этап адаптации обычно наступает в конце первого года жизни.

Так как правое полушарие изменило направление деятельности на обработку воспринимаемой информации, то для сохранения эффективности левое должно переключиться на анализ транслируемой информации. К этому моменту должен накопиться достаточный опыт по изменению окружающего пространства, из прежней правополушарной деятельности. Соответственно, левое полушарие сможет систематизировать данный опыт, и на этой основе построить долгосрочные цели. Однако левое полушарие имеет противоположную правому направленность. В итоге на этом этапе развития система приобретет цели, связанные с изменением окружающего пространства. Однако полученный правым полушарием опыт может не иметь достаточной контрастности. Тогда он не позволит выявить закономерности. Следовательно, увеличение предсказуемости, которое мы описали для правого полушария, не произойдёт для левого. В этом случае возможна фиксация типа взаимодействия в левом полушарии.

Вернемся к рассмотрению второго этапа адаптации правого полушария. Теперь получение информации происходит через внешние её источники: людей или различные информационные носители. Целью является поиск алгоритмов максимального извлечения удовольствия из объектов, либо алгоритмов перевода их в наиболее безопасное состояние. Окружающие люди также являются объектами, о манипуляции с которыми собирается информация.

Если среда достаточно стабильна, ребёнок найдет наиболее эффективные алгоритмы действий. В таком случае будут конкретные источники наибольшей выгоды или наибольшей опасности. Тогда окружающая среда изменится по отношению к человеку, о чём будет написано ниже. Но возможна и другая ситуация, когда различные источники будут в разное время либо более выгодны, либо менее. Такая среда будет содержать несколько в среднем схожих по интенсивности источников. В итоге появится несколько схожих по эффективности алгоритмов и системе придётся продолжать поиск лучшей активности. В этом случае фиксируется стратегия системы, соответствующая предсказуемой, но скудной среде. К. Юнг назвал тип людей со сходными особенностями прямого взаимодействия с окружением - «интровертный ощущающий тип». Описанные на данный момент два типа окружающей среды заметно влияют также на конституцию человека, так как они свойственны периоду раннего развития. В скудных системах людям более свойственна плотная конституция [39], поэтому люди, чей тип непосредственного поведения зафиксировался на первых двух этапах адаптации, являются менее астеническими.

В случае успешной адаптации деятельности под внешние источники полезного или разрушающего сигнала, эти источники получат точную определённость. В таком случае появится возможность либо включить данные источники в свою надсистему, либо их устранить. При этом вероятность такого события системе не известна. Получается, система открывает для себя иную окружающую среду, с непредсказуемыми, но интенсивными источниками информации. Следовательно, снова изменится характер деятельности системы в непосредственных ситуациях, за которые отвечает правое полушарие.

В момент новой смены стратегии правого полушария, изменится и деятельность левого полушария. Но только если не произошло фиксации на предыдущем типе активности. Теперь левое полушарие начнет анализировать и систематизировать информацию о способах манипулирования окружающими объектами. А значит, в этой сфере будут и новые долгосрочные жизненные цели. В случае если опыт правого полушария имеет малый контраст, то также возможна фиксация текущих свойств деятельности левого полушария [40].

На третьем этапе адаптации правого полушария будут наблюдаться попытки либо устранения наибольших источников внешних помех [41], либо стремление получить контроль над источниками максимального удовольствия. Практически всегда такими источниками будут окружающие люди [42]. Информация, передаваемая во внешний мир, будет проявляться через определённую активную «роль» ребёнка [43; 44; 45]. Данный этап начинается в районе трёх лет. Описанная деятельность может привести к увеличению предсказуемости, а, следовательно, и изменению доступной окружающей среды. Но если успех будет не ста- 


\section{Психология развития}

бильным, произойдёт фиксация типа прямых взаимодействий с окружающей средой, зависящих от правого полушария. Тогда человек продолжит стремиться избегать ситуаций подчинённости, либо наоборот будет пытаться доминировать [46]. Другими словами, система будет направлена либо на исключение интенсивных источников из своей надсистемы, либо, наоборот, на создание с ними надсистемы. У К. Юнга люди, демонстрирующие подобное поведение, отнесены к «экстравертному интуитивному» типу.

В случае увеличения предсказуемости результатов деятельности на третьем этапе адаптации правого полушария, окружающая среда, доступная системе, станет предсказуемо изобильной. Появится потребность сменить тип взаимодействия с нею. Теперь достаточно будет продолжать успешные роли, а вследствие предсказуемости появится возможность снизить затраты, заменив ролевые действия на внешние атрибуты ролей [47; 48]. Эта смена деятельности происходит приблизительно в шестилетнем возрасте. Если ожидаемый результат сохранится, то не будет стимула что-либо менять - тип активности зафиксируется. В этом отличие от предыдущих этапов адаптации. При такой ситуации фиксация способа обработки информации правого полушария закрепляется в случае успеха, а не наоборот. Это связано с тем, что среда теперь предоставляет системе максимум ресурсов, либо безопасности. Деятельность системы теперь будет направлена на включение себя в имеющуюся надсистему социальных символов, с максимальной из известных ей выгодой. В случае отрицательной направленности правого полушария, появится стремление включить себя в символическую надсистему, которая максимально удалена от известных системе опасностей [49]. Появляется потребность соответствовать некоторому «образу», релевантному текущей ситуации. В модели К. Юнга тип людей с подобным поведением в прямом общении был назван «интровертный интуитивный» тип.

Одновременно с переходом правого полушария на четвёртый этап адаптации, соответствующий приёму информации, левое полушарие перейдёт на третий этап адаптации. Конечно, такой переход произойдёт, только если левое полушарие не зафиксирует ранее свой тип обработки информации. Все остальные особенности также совпадают с предыдущими этапами адаптации.

Обычно круг общения людей постоянно меняется. Следовательно, и на четвёртом этапе адаптации, правое полушарие может столкнуться с новыми людьми, источниками внешних сигналов.
Эмоциональное отношение новых людей к ранее воспринятому «образу» человека может отличаться от отношения тех людей, под которых до этого произошла адаптация. Если фиксация поведения ещё не произошла, то такое изменение среды может вызвать дальнейшую адаптацию. Эта новая смена активности происходит в возрасте, примерно равном десяти годам.

До этого система оперировала с окружающими людьми как с объектами, приблизительно равными между собой по свойствам. Однако на данном, пятом этапе появляется потребность адаптации под их индивидуальные предпочтения. Ведь именно различие в эмоциональном отношении значимых людей не позволяет создать одну единую со всеми символическую надсистему. Однако отношение людей к различным «образам» достаточно предсказуемо при накопившемся опыте активностей. Предсказуемы в том числе и наиболее значимые люди, источники ресурсов или опасности. Следовательно, характеристики ресурсной базы сохранятся. Но меняются носители информации во взаимодействии. Теперь ими будут не физические объекты и люди как объекты, а люди как субъекты. Символические надсистемы сменяются социальными [50].

На этом этапе адаптации правого полушария система стремится в прямом общении либо достичь положительной лояльности к себе, либо избежать появления отрицательной лояльности [51]. Что означает соответствие по свойствам ожиданиям отдельных значимых людей, для включения в их надсистему, либо избегание резкого диссонанса с данными ожиданиями, чтобы исключить возможность противоречия. Данная лояльность, или можно сказать «гудвилл», становится частью общей надсистемы [52]. Критерием служит мнение людей, с которыми происходит коммуникация. Другими словами, человек будет выполнять одобряемые действия и избегать осуждаемых [53; 54; 55].

Переход правого полушария к пятому этапу адаптации не приведёт к переходу левого полушария на четвёртый. Так как пятый этап является, как и четвёртый, «интровертным», а данная спецификация разделяется между полушариями. К тому же, выше был описан момент перехода внимания с «физического» представления источников внешнего сигнала на «социальное». Восприятие окружающих людей в качестве объектов сменилось на восприятие их в роли субъектов. Однако многие объекты окружающего мира, которые образовывали с человеком общую надсистему, не являются субъектами. Потребность в работе с «физической» составляющей окружающего мира сохраняется. 


\section{Психология и психотехника 8(95) • 2016}

Работа с «социальной» и с «физической» составляющими среды также разделяется между полушариями. Последнее означает, что после перехода правого полушария на «социальные» этапы адаптации, левое полушарие останется на «физических», т.е. на третьем этапе.

Если на этом, пятом этапе адаптации среда вновь станет предсказуемой, то тип деятельности правого полушария зафиксируется [56]. Данный тип непосредственных проявлений человека К. Юнг назвал «интровертный чувствующий» тип. Однако может случиться ситуация, когда окружающие люди проявят не достаточно стабильную эмоциональную реакцию на действия системы, несмотря на общие одобрение или неодобрение. В этом случае требуемый эффект не будет достигнут, а значит среда приобретёт характеристики не предсказуемой. Величина награды или ущерба по-прежнему велика. В таких условиях человек сосредоточится не на формировании эмоционального отношения, мнения окружающих, а на формировании эмоционального впечатления. Система переходит к управлению окружающими людьми, их стремлениями и потребностями. На этом этапе адаптации человек заинтересован в создании выгодного эффекта у окружающих, основанного на позиционировании себя ка ресурса. Такой эффект формирует внешний спрос на включение его системы в общую надсистему. В случае отрицательной направленности будет иметь место тяга к избеганию негативного эффекта, который мог бы привести к внешней агрессии.

Переход правого полушария на шестой этап адаптации позволит левому полушарию перейти на четвёртый. Если оно ранее не зафиксировалось на третьем, что могло иметь место в случае недостаточности опыта правого полушария на его третьем этапе адаптации.

Шестой этап адаптации правого полушария также зафиксируется в случае успеха. Такая фиксация непосредственной деятельности соответствует «экстравертному чувствующему» типу по классификации К. Юнга. При этом вероятна ситуация, при которой окружающие не будут воспринимать транслируемое впечатление в полной мере. В этом случае среда приобретёт характеристики более скудной, а значит изменится и тактика человека.

Сопротивление транслируемому сигналу возможно, когда у людей есть прочная связь с глобальными надсистемами, требующими от своих элементов определённых свойств. Если такие люди преобладают в окружении системы, то система вынуждена также стремиться войти в общую надсистему. Либо для объединения в надсистему с людь- ми, являющимися источниками ресурсов. Либо для избегания взаимодействия с источниками опасности. Для этого потребуется соответствовать необходимым в ней свойствам. Это увеличит предсказуемость, однако эмоциональное отношение людей к самому человеку будет заменено отношением к его надсистемам. Прямой выигрыш человека в такой среде станет гораздо меньше. Среда приобретает свойства предсказуемой, но скудной. Люди, с положительным опытом деятельности в таком окружении, у которых зафиксировался соответствующий тип прямого взаимодействия со средой, были отнесены К. Юнгом к «интровертному мыслительному» типу.

Однако на данный, седьмой этап адаптации правое полушарие не сможет перейти, если левое полушарие ранее перешло на четвёртый этап адаптации. Оба полушария не могут проявлять интровертную активность. Перейти на другой, экстравертный этап левое полушарие не сможет. Это ограничение связано, во-первых, с тем, что вернуться на предыдущие этапы с меньшими ресурсами невозможно. Во-вторых, на шестой этап адаптации левое полушарие перейти не имеет возможности, по причине того, что в этом случае, оба полушария будут связаны с «социальной» составляющей мира. Получается, правое полушарие должно перейти сразу на восьмой, также экстравертный этап адаптации. Однако логика следования уровней адаптации всё же требует считать седьмым этапом именно описанный выше. На седьмой этап развития правое полушарие переходит с пятого, в тех случаях, когда левое ранее установилось на экстравертном этапе.

Поэтому при неэффективности деятельности, направленной на эмоциональное впечатление, произойдёт переход сразу на восьмой этап адаптации. На восьмом уровне адаптации правого полушария человек будет стремиться создавать общую надсистему только с близкими к себе по свойствам людьми. Вероятность появления таких людей достаточно низка, зато затраты на взаимодействие также будут минимальны. Выигрыш от коммуникации с ними не высок. Что является следствием малого различия в свойствах, а значит и в способах взаимодействия со средой, внешней к их надсистеме. Как следствие устойчивость общей надсистемы к внешним воздействиям будет не слишком велико. Получается, ресурсная база для системы будет скудной. В случае же отрицательной направленности правого полушария, будет иметь место стремление дистанцироваться от людей, значительно отличающихся по своим свойствам мышления. По модели К. Юнга подоб- 
ная деятельность характеризует «экстравертный мыслительный» тип.

Если какое-либо полушарие зафиксировало тип взаимодействия с окружающим миром на более ранних этапах адаптации, то другое полушарие сможет продолжить адаптацию только минуя этапы, совпадающее по характеристике приём/ трансляция информации, или другими словами интроверсия/экстраверсия. Если оба полушария прервут адаптацию на «физических» этапах, не дойдя до обработки информации о «социальной» составляющей мира, то это приведёт к аутизму в различной форме, в зависимости от достигнутых этапов [57].

Возможны ситуации, когда окружающая среда вынудит оба полушария перейти на «социальные» этапы. Тогда противоречие с большой вероятностью приведёт к появлению шизофрении [58]. Наиболее вероятна подобная ситуация, если левому полушарию характерен тип обработки информации, связанный с «социальной» составляющей мира, а правое полушарие остановилось на взаимодействии с «физической» составляющей мира. Именно правое полушарие более подвержено влиянию окружающей среды, поэтому при существенных и долгих нарушениях её свойств произойдёт дальнейшее развитие адаптации даже с ранее зафиксированного этапа. Наиболее вероятен переход с четвёртого на пятый этап. Существенно менее вероятен, но также возможен переход с третьего на шестой этап адаптации правого полушария, при пятом или седьмом этапе развития левого полушария.

В норме, при фиксации какого-либо этапа адаптации правого полушария, для левого полушария доступны только два возможных этапа, отличающихся по специфике обработки информации. Верна и обратная зависимость, при фиксации левого полушария, правому полушарию остаются доступными для остановки только два из восьми этапов.

\section{Заключение}

Предложено краткое обоснование развития и формирования психики человека на основании теории систем. Человек рассматривался как адаптирующаяся к окружающей среде система. Показано, что первые четыре этапа адаптации направлены на взаимодействие с окружающими объектами, а последующие четыре - с окружающими субъектами. В процессе развития механизмов деятельности с объектами, меняются характеристики взаимодействующей с человеком среды. Точнее, увеличива- ются предсказуемость или величина ресурсной базы. Также, описаны причины, которые приводят к остановке адаптации и фиксации на определённом этапе. Таковыми причинами является соответствие характеристик окружающей среды деятельности системы.

Соответствие способа взаимодействия со средой и характеристик среды является причиной фиксации и на последующих четырёх уровнях адаптации. Хотя при взаимодействии с субъектами иная картина взаимного влияния среды и человека. Слишком скудная или непредсказуемая ресурсная база провоцирует дальнейшее развитие способов действий.

В первой части было выведено, что для каждой системы существует четыре возможных типа источников ресурсов или опасностей, относительно характеристик самой системы. При этом для различных ресурсов или опасностей, доступных системе, тип среды может быть различным. Отсюда получается, что возможны четыре типа среды физических объектов и четыре типа среды социальных субъектов. Взаимодействие с этими двумя классами ресурсов или опасностей и было описано в статье. Именно это взаимодействие наиболее заметно в общении, а потому наиболее важно для понимания процессов коммуникации между людьми. Взаимодействие с другими классами ресурсов или опасностей может также иметь независимые характеристики.

Человек обладает двумя, существенно автономными, «устройствами» обработки информации, полушариями мозга, что позволяет эффективно взаимодействовать одновременно и с «физической» и с «социальной» средами. Между полушариями также делится обработка информации по следующим параметрам: приём или трансляция информации; взаимодействие с ресурсами или с угрозами; краткосрочные цели или будущая перспектива. Последняя характеристика влияет на то, что наиболее заметны проявления человека связанные с правым полушарием, отвечающим за краткосрочные цели. Так как такая специфика означает большую направленность на непосредственное взаимодействие. Именно по достигнутому правым полушарием этапу адаптации была построена типология личностей К. Юнга, соотнесение с которой также имеется в статье. Представленная модель показывает, почему К. Юнг смог выделить именно восемь типов личностей.

Таким образом в статье приведена попытка применения теории систем в области психологии для получения лучшего представления о работе психики человека. 


\section{Психология и психотехника 8(95) • 2016}

\section{Список литературы:}

1. Анохин П.К. Философские аспекты теории функциональных систем. М.: Наука, 1978. 395 с.

2. Пригожин И., Стенгерс И. Порядок из хаоса. Новый диалог человека с природой. М.: Прогресс, 1986. 432 с.

3. Скляров, И.Ф. Моделирование системы. Деп. в ВИНИТИ. 1996, 1699-В86.

4. Бриллюэн Л. Термодинамика, статистика и информация // Успехи физических наук. 1962. № 77(2). С. 337-352

5. Богданов А.А. Тектология-всеобщая организационная наука: в 2-х кн. М.: Экономика, 1989. 304+351 c.

6. Работнов Т.А. История фитоценологии. М.: Аргус, 1995. 158 с.

7. Deygout C., Gault A., Sarrazin F., Bessa-Gomes C. Impact of food predictability on social facilitation by foraging scavengers // Behavioral Ecology. 2010. No. 21(6). P. 1131-1139.

8. Clark J.D., Brandt S.A. From Hunters to Farmers: The Causes and Consequences of Food Production in Africa. Berkeley: University of California Press, 1984. 434 p. P. 256-258.

9. Abel T. Complex adaptive systems, evolutionism, and ecology within anthropology: interdisciplinary research for understanding cultural and ecological dynamics // Georgia journal of ecological anthropology. 1998. No. 2. P. 6-29.

10. Eysenck H.J., Eysenck M. Mindwatching: Why People Behave the Way They Do. New York: Anchor Press/Doubleday, 1983. 344 p.

11. Медоуз Д., Рандерс Й., Медоуз Д. Пределы роста. 30 лет спустя. М.: ИКЦ «Академкнига», 2007. 342 с.

12. Реброва Н.П. Физиология сенсорных систем. СПб.: НП «Стратегия будущего», 2007. 106 с.

13. Клепиков 0, Муразанов А. Система структурно-динамического профайлинга // PSYCHEYA. The new economist. 2014. [Электронный ресурс] URL: http://neweconomist.ru/files/Psychea_fmed.pdf (дата обращения 02.04.2016).

14. Субботина Л.Ю. Психология защитного поведения. Ярославль: ЯрГУ, 2006. 220 с.

15. Анохин П.К. Принципы системной организации функций. М.: Наука, 1973. 561 с.

16. Доброборский Б.С. Термодинамика биологических систем. СПб.: СПбГМА им. И.И. Мечникова, 2006. 52 с.

17. Farroni T., Menon E., Rigato S., Johnson M.H. The perception of facial expressions in newborns // Eur J Dev Psychol. 2007. No. 4(1). P. $2-13$

18. Bollen A., Murray L. Can newborn babies imitate? // NCT Journal. 2011. No. 11(13). P. 14-15.

19. Gaussier P., Boucenna S., Nadel J. Emotional interactions as a way to structure learning // Proceedings of the Seventh International Conference on Epigenetic Robotics / EPIROB 2007. Lund University Cognitive Studies. 2007. No. 135. P. 193-194.

20. de Bruin J.O., Hoogstra-Klein M.O., Mohren G.M.J., Arts B.J.M. Complexity of Forest Management: Exploring Perceptions of Dutch Forest Managers // Forests. 2015. No. 6(9). P. 3237-3255.

21. Ames C., Archer J. Achievement Goals in the Classroom: Student's Learning Strategies and Motivation Process // Journal of Educational Psychology. 1988. Vol. 80. No. 3. P. 260-267.

22. Elliot A.J., Thrash T.M. Achievement Goals and the Hierarchical Model of Achievement Motivation // Educational Psychology Review. 2001. Vol. 13. No. 2. P. 139-156.

23. Carveth D.L. Psychoanalysis and Social Theory: The Hobbesian Problem Revisted // Psychoanalysis \& Contemporary Thought. 1984. No. 7(1). P. 43-98.

24. Bandura A. (1999). A social cognitive theory of personality // Pervin L. \& John 0. (Ed.). Handbook of personality. 2nd ed. New York: Guilford Publications, 1999. P. 154-196. (Reprinted in Cervone D. \& Shoda Y. [Eds.]. The coherence of personality. New York: Guilford Press.)

25. Pavlov I.P. Conditioned reflexes: an investigation of the physiological activity of the cerebral cortex / Translated by G.V. Anrep. New York: Dover Publications F, 1927.

26. Лурия А.Р. Основы нейропсихологии. М.: Изд. центр «Академия», 2006. 384 с.

27. Голдберг Э. Управляющий мозг: Лобные доли, лидерство и цивилизация / Пер. с англ. Д. Бугакова. М.: Смысл, 2003. $335 \mathrm{c}$.

28. Брехман Г.И. Эмоциональная жизнь плода: от смутных догадок к научным исследованиям // Жіночий Лікар. 2011. № 2. С. $10-15$.

29. Малошонок Н.Г., Семёнова Т.Ф., Терентьев Т.А. Учебная мотивация студентов российских вузов: возможности теоретического осмысления // Вопросы образования. 2015. № 3. С. 92-121.

30. Grof S. Realms of the human unconscious: Observations from LSD research. London, UK: Souvenir Press, 1996. 58 p.

31. Пиаже Ж. Психология интеллекта // Пиаже Ж. Избранные психологические труды. Психология интеллекта. Генезис числа у ребенка. Логика и психология. М.: Просвещение, 1969. С. 587-588.

32. Erikson E.H. Childhood and society. London: Vintage, 1995. 400 p.

33. Фрейд 3. Тотем и табу. М.: Олимп. 1997. 448 с. С. 184-216.

34. Юнг К.Г. Психологические типы. М.: Университетская книга: АСТ, 1998.720 с.

35. Piaget J. The Psychology of Intelligence. London: Routledge Classics, 2001. 204 p.

36. Elkonin D.B. On the problem of periodization of mental development in children // Questions of psychology. 1971 . No. 4. P. 6-20.

37. Богачкина Н.А. Психология: конспект лекций. М.: Эксмо, 2008. 160 с.

38. Шпаковский Н. Человек и техническая система (часть 2) // Генератор. 2003. [Электронный pecypc] URL: http://www. gnrtr.ru/Generator.html?pi=200\&cp=3 (дата обращения 20.03.2016).

39. Московченко О.Н., Катцина Т.А., Гончаревич Н.А., Шайдурова О.В. Антропология. Конспект лекций. Красноярск: Сиб. Федер. Ун-т, 2012.78 с.

40. Баранова М.Л. Справочник руководителя дошкольного образовательного учреждения. Организация психолого-педагогической помощи детям раннего возраста. Ростов н/Д: Феникс, 2005. 375 с.

41. Эльконин Д.Б. Детская психология. М.: Академия, 2007. 384 с. 


\section{Психология развития}

42. Лисина М.И. Формирование личности ребенка в общении. СПб.: Питер, 2009. 410 с.

43. Эльконин Д.Б. Психология игры. М.: Педагогика, 1978. 304 с.

44. Выготский Л.С. Игра и её роль в психическом развитии ребёнка // Вопросы психологии. 1966. № 6. С. 62-77.

45. Пиаже Ж. Теория, эксперименты, дискуссии. М.: Гардарика, 2001. 624 с.

46. Райх В. Анализ характера. М.: Эксмо, 2000. 528 с.

47. Божович Л.И. Психологические вопросы готовности ребёнка к школьному обучению // Вопросы психики ребенка дошкольного возраста / Под ред. А.Н. Леонтьева. М.: Изд-во АПН РСФСР, 1948. 464 с.

48. Выготский Л.С. Собр. соч. М.: Педагогика, 1984. С. 244-268.

49. Бурдьё П. Практический смысл. СПб.: Алетейя, 2001. 562 с.

50. Коулман Дж. Капитал социальный и человеческий // Общественные науки и современность. 2001. № 3. С. 22-139.

51. Райхельд Ф., Марки Р. Искренняя лояльность. Ключ к завоеванию клиентов на всю жизнь. М.: Манн, Иванов и Фербер, 2013. 352 c.

52. Ершова Е.А. Гудвилл бизнеса. М.: Статут, 2013. 223 с.

53. Божович Л.И. Проблемы формирования личности / Под ред. Д.И. Фельдштейна. 2-е изд. М.: Институт практической психологии; Воронеж: НПО «МОДЭК», 1997. 352 с.

54. Выготский Л.С. Педология подростка. М.; Л.: Изд-во БЗО при педфаке 2-го МГУ, 1931. 504 с.

55. Эльконин Д.Б. Избранные психологические труды. М.: Педагогика, 1989. 560 с.

56. Личко А.Е. Психопатии и акцентуации характера у подростков. Л.: Медицина, 1983. 256 с.

57. Аппе Ф. Введение в психологическую теорию аутизма. М.: Теревинф, 2006. 216 с.

58. Green M., Horan W., Lee J. Social cognition in schizophrenia // Nature Reviews Neuroscience. 2015. No. 16(10). P. 620-631.

\section{References (transliterated):}

1. Anokhin P.K. Filosofskie aspekty teorii funktsional'nykh sistem. M.: Nauka, 1978. 395 s.

2. $\quad$ Prigozhin I., Stengers I. Poryadok iz khaosa. Novyi dialog cheloveka s prirodoi. M.: Progress, 1986. $432 \mathrm{~s}$.

3. Sklyarov I.F. Modelirovanie sistemy. Dep. v VINITI, 1996. 1699-V86/

4. Brillyuen L. Termodinamika, statistika i informatsiya // Uspekhi fizicheskikh nauk. 1962. № 77(2). S. 337-352.

5. Bogdanov A.A. Tektologiya-vseobshchaya organizatsionnaya nauka: v 2-kh kn. M.: Ekonomika, 1989. 304+351 s.

6. Rabotnov T.A. Istoriya fitotsenologii. M.: Argus, 1995. $158 \mathrm{s.}$

7. Deygout C., Gault A., Sarrazin F., Bessa-Gomes C. Impact of food predictability on social facilitation by foraging scavengers // Behavioral Ecology. 2010. No. 21(6). P. 1131-1139.

8. Clark J.D., Brandt S.A. From Hunters to Farmers: The Causes and Consequences of Food Production in Africa. Berkeley: University of California Press, 1984. 434 p. P. 256-258.

9. Abel T. Complex adaptive systems, evolutionism, and ecology within anthropology: interdisciplinary research for understanding cultural and ecological dynamics // Georgia journal of ecological anthropology. 1998. No. 2. P. 6-29.

10. Eysenck H.J., Eysenck M. Mindwatching: Why People Behave the Way They Do. New York: Anchor Press/Doubleday, 1983. 344 p.

11. Medouz D., Randers I., Medouz D. Predely rosta. 30 let spustya. M.: IKTs “Akademkniga”, 2007. 342 s.

12. Rebrova N.P. Fiziologiya sensornykh sistem. SPb.: NP «Strategiya budushchego», 2007.106 s.

13. Klepikov 0, Murazanov A. Sistema strukturno-dinamicheskogo profailinga // PSYCHEYA. The new economist. 2014. [Elektronnyi resurs] URL: http://neweconomist.ru/files/Psychea_fmed.pdf (data obrashcheniya 02.04.2016).

14. Subbotina L.Yu. Psikhologiya zashchitnogo povedeniya. Yaroslavl': YarGU, 2006. 220 s.

15. Anokhin P.K. Printsipy sistemnoi organizatsii funktsii. M.: Nauka, 1973. $561 \mathrm{s.}$

16. Dobroborskii B.S. Termodinamika biologicheskikh sistem. SPb.: SPbGMA im. I.I. Mechnikova, 2006. $52 \mathrm{s.}$

17. Farroni T., Menon E., Rigato S., Johnson M.H. The perception of facial expressions in newborns // Eur J Dev Psychol. 2007. No. 4(1). P. 2-13

18. Bollen A., Murray L. Can newborn babies imitate? // NCT Journal. 2011. No. 11(13). P. 14-15.

19. Gaussier P., Boucenna S., Nadel J. Emotional interactions as a way to structure learning // Proceedings of the Seventh International Conference on Epigenetic Robotics / EPIROB 2007. Lund University Cognitive Studies. 2007. No. 135. P. 193194.

20. de Bruin J.O., Hoogstra-Klein M.O., Mohren G.M.J., Arts B.J.M. Complexity of Forest Management: Exploring Perceptions of Dutch Forest Managers // Forests. 2015. No. 6(9). P. 3237-3255.

21. Ames C., Archer J. Achievement Goals in the Classroom: Student's Learning Strategies and Motivation Process // Journal of Educational Psychology. 1988. Vol. 80. No. 3. P. 260-267.

22. Elliot A.J., Thrash T.M. Achievement Goals and the Hierarchical Model of Achievement Motivation // Educational Psychology Review. 2001. Vol. 13. No. 2. P. 139-156.

23. Carveth D.L. Psychoanalysis and Social Theory: The Hobbesian Problem Revisted // Psychoanalysis \& Contemporary Thought. 1984. No. 7(1). P. 43-98.

24. Bandura A. (1999). A social cognitive theory of personality // Pervin L. \& John 0. (Ed.). Handbook of personality. 2nd ed. New York: Guilford Publications, 1999. P. 154-196. (Reprinted in Cervone D. \& Shoda Y. [Eds.]. The coherence of personality. New York: Guilford Press.)

25. Pavlov I.P. Conditioned reflexes: an investigation of the physiological activity of the cerebral cortex / Translated by G.V. Anrep. New York: Dover Publications F, 1927.

26. Luriya A.R. Osnovy neiropsikhologii. M.: Izd. tsentr «Akademiya», 2006. $384 \mathrm{~s}$.

27. Goldberg E. Upravlyayushchii mozg: Lobnye doli, liderstvo i tsivilizatsiya / Per. s angl. D. Bugakova. M.: Smysl, 2003.335 s. 


\section{Психология и психотехника 8(95) • 2016}

28. Brekhman G.I. Emotsional'naya zhizn' ploda: ot smutnykh dogadok k nauchnym issledovaniyam // Zhinochiľ Likar. 2011. № 2. S. 10-15.

29. Maloshonok N.G., Semenova T.F., Terent'ev T.A. Uchebnaya motivatsiya studentov rossiiskikh vuzov: vozmozhnosti teoreticheskogo osmysleniya // Voprosy obrazovaniya. 2015. № 3. S. 92-121.

30. Grof S. Realms of the human unconscious: Observations from LSD research. London, UK: Souvenir Press, 1996.58 p.

31. Piazhe Zh. Psikhologiya intellekta // Piazhe Zh. Izbrannye psikhologicheskie trudy. Psikhologiya intellekta. Genezis chisla u rebenka. Logika i psikhologiya. M.: Prosveshchenie, 1969. S. 587-588.

32. Erikson E.H. Childhood and society. London: Vintage, 1995. 400 p.

33. Freid Z. Totem i tabu. M.: Olimp. 1997. 448 s. S. 184-216.

34. Yung K.G. Psikhologicheskie tipy. M.: Universitetskaya kniga: AST, 1998. $720 \mathrm{~s}$.

35. Piaget J. The Psychology of Intelligence. London: Routledge Classics, 2001. $204 \mathrm{p}$.

36. Elkonin D.B. On the problem of periodization of mental development in children // Questions of psychology. 1971. No. 4. P. 6-20.

37. Bogachkina N.A. Psikhologiya: konspekt lektsii. M.: Eksmo, 2008. $160 \mathrm{~s}$.

38. Shpakovskii N. Chelovek i tekhnicheskaya sistema (chast' 2) // Generator. 2003. [Elektronnyi resurs] URL: http://www.gnrtr. $\mathrm{ru} /$ Generator.html?pi=200\&cp=3 (data obrashcheniya 20.03.2016).

39. Moskovchenko O.N., Kattsina T.A., Goncharevich N.A., Shaidurova O.V. Antropologiya. Konspekt lektsii. Krasnoyarsk: Sib. Feder. Un-t, 2012. 78 s.

40. Baranova M.L. Spravochnik rukovoditelya doshkol'nogo obrazovatel'nogo uchrezhdeniya. Organizatsiya psikhologopedagogicheskoi pomoshchi detyam rannego vozrasta. Rostov: Feniks, 2005. 375 s.

41. El'konin D.B. Detskaya psikhologiya. M.: Akademiya, 2007. 384 s.

42. Lisina M.I. Formirovanie lichnosti rebenka v obshchenii. SPb.: Piter, 2009. 410 s.

43. El'konin D.B. Psikhologiya igry. M.: Pedagogika, 1978. $304 \mathrm{~s}$.

44. Vygotskii L.S. Igra i ee rol' v psikhicheskom razvitii rebenka // Voprosy psikhologii. 1966. № 6. S. 62-77.

45. Piazhe Zh. Teoriya, eksperimenty, diskussii. M.: Gardarika, 2001. 624 s.

46. Raikh V. Analiz kharaktera. M.: Eksmo, 2000. 528 s.

47. Bozhovich L.I. Psikhologicheskie voprosy gotovnosti rebenka k shkol'nomu obucheniyu // Voprosy psikhiki rebenka doshkol'nogo vozrasta / Pod red. A.N. Leont'eva. M.: Izd-vo APN RSFSR, 1948. 464 s.

48. Vygotskii L.S. Sobranie sochinenii. M.: Pedagogika, 1984. S. 244-268.

49. Burd'e P. Prakticheskii smysl. SPb.: Aleteiya, 2001. $562 \mathrm{s.}$

50. Koulman Dzh. Kapital sotsial'nyi i chelovecheskii // Obshchestvennye nauki i sovremennost'. 2001. № 3. S. 22-139.

51. Raikhel'd F., Marki R. Iskrennyaya loyal'nost'. Klyuch k zavoevaniyu klientov na vsyu zhizn'. M.: Mann, Ivanov i Ferber, 2013. $352 \mathrm{~s}$.

52. Ershova E.A. Gudvill biznesa. M.: Statut, 2013. 223 s.

53. Bozhovich L.I. Problemy formirovaniya lichnosti / Pod red. D.I. Fel'dshteina. 2-e izd. M.: Institut prakticheskoi psikhologii; Voronezh: NPO «MODEK», 1997. 352 s.

54. Vygotskii L.S. Pedologiya podrostka. M.; L.: Izd-vo BZO pri pedfake 2-go MGU, 1931. 504 s.

55. El'konin D.B. Izbrannye psikhologicheskie trudy. M.: Pedagogika, 1989. $560 \mathrm{s.}$

56. Lichko A.E. Psikhopatii i aktsentuatsii kharaktera u podrostkov. L.: Meditsina, 1983. $256 \mathrm{~s}$

57. Appe F. Vvedenie v psikhologicheskuyu teoriyu autizma. M.: Terevinf, 2006. 216 s.

58. Green M., Horan W., Lee J. Social cognition in schizophrenia // Nature Reviews Neuroscience. 2015. No. 16(10). P. 620-631. 